\title{
Parametric Analysis of Hot Gas Welding for PP+EPR Blend and Evaluation of Welds in Tensile Conditions
}

\author{
Sumedh Ingle \\ M. Tech student (Production engg) \\ Dept. of Mechanical Engineering, \\ GCOE, Amravati, India.
}

\begin{abstract}
The primary objective of the existing work is to evaluate hot gas welding technique for PP composite material and carrying out analysis over the critical parameters (air flow rate, temperature, weld time) to determine material weld strength in tensile conditions. Polypropylene blend with elastomer have wide application in engineering areas due to their desired properties but due to these changed properties over existing one recycling get affected and became difficult so their reparability should be considered. Hot gas welding helps to join the cracks and restore defects in it. Extracting the optimized values from critical parameters will help to make the method more efficient and effective. Tensile probing carried over specimen by considering ASTM standards assist to know former and later tensile conditions of welded joints.
\end{abstract}

Keywords:- Hot gas welding, PP+EPR blends, Air flow rate, Parameters, Plastic joining.

\section{INTRODUCTION}

Plastic is an engineering material under polymer group used over large scale in different fields and industry. It has various advantages over conventional materials the most significant is being high strength to weight proportions. It has transmuted the work in the field of space scrutiny, nanotechnology, medical and engineering. It is becoming highly desired engineering materials but its joining techniques are not used at satisfactory level instead they are recycled which consumes more energy so joining method in form of welding should be used. Minimizing the time and improving quality are the key objectives for any industries. In recent years, different industries has led to increase the utilization of light weight metallic and non metallic materials with the seek of achieving targeted adaptability. Joining technology is an integral part of manufacturing process and efforts has spent to develop and demonstrate the suitability of various process of application in both design and structural fabrication.

Plastic joining is a method of joining two or more materials with the help of some external means. There is a huge requirement of plastic joining because of limitation in manufacturing for complicated work design. The process of joining mainly includes interlocking of two surfaces so that they get stuck with each other on the basis of molecular and non molecular structure. To make product highly reliable,

\author{
M. J. Deshmukh \\ Professor \\ Dept. of Mechanical Engineering, \\ GCOE, Amravati, India.
}

joining technique must choose in a appropriate manner considering influential factors. Joining methods for plastics are classified under different groups each methods have its own pros and limitations.

Plastic Welding is a joining process in which two parts are eventually melted till softened and interface are joined. The work pieces are fused together with or without filler material. Plastic welding is reported in ISO 472 as a process of joining softened surface of material generally with the help of heat[4]. There are different types welding methods depends on heat application modes may be internal or external. Some of the highly used welding techniques are Hot tool welding, Hot gas welding, Extrusion welding, Friction stir welding, Laser welding, Ultrasonic welding etc. Weldability of plastics is an important factor for selection of the process.

\section{PROCESS AND MATERIAL EXPLANATION}

\section{$>$ Hot gas welding}

Hot gas welding is an external heating method which is simple and portable, used for fabrication and repairs of product at different stages. The strength of joint is totally depends on bonding properties of filler stuff with actual surface. For carrying out welding by hot gas method hot gun is used, this gun consist of heating coils which create heat by consuming electrical energy. The air mass flow and temperature can be regulated in specific range. It is used in fabrication of storage containers, the sealing of roof or floor membranes repairs and widely employed to plastic constructions.

Hot gas welding is one of the external heating methods and it was patented by Reinhardt in 1940 [8]. In this method, a weld groove and a welding rod were heated with hot gas stream until they soften sufficiently to fuse then the welding rod is pressed into the weld groove. Hot gas method is the earliest method of joining thermo plastics sheets and dates from world war II when it was used to repair bullet riddle, acrylic cockpit canopies [12]. At that stage plastic was not use as a predominant material in engineering fields. It is primarily used for repairs or individual manufacturing needs of small or complex components. In starting period of $20^{\text {th }}$ century, there was adaptability of different materials in various fields, in that development of plastics attracted many researchers due to its light weight and durable qualities. As the plastic consumption increase from mid of $20^{\text {th }}$ century, 
production of plastic as increase over a large which start affecting environment at various stages. So production of plastic is to be cut down instead repair of plastics should take place in wide manner.

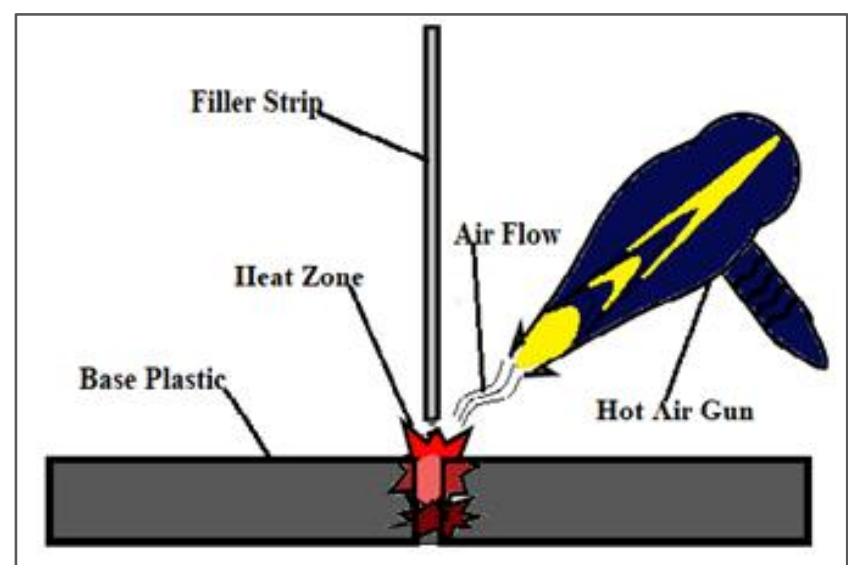

Fig 1:- Hot Gas Welding.

In this method stream of hot gas is directed towards the welding zone which cause the plastic area to melt and soften which can be joined by applying pressure and adding filler material as shown in fig.1. The temperature of hot gas stream need to achieve softening state it may vary for different plastics depends on plastic compositions. The gas temperature generally held between 200 to $650^{\circ} \mathrm{C}$. Filler rod may be of different cross section rectangular, circular, oval etc. air volume or temperature can be adjusted in range and the nozzle can be easily replaced for suitable working manner.

\section{$>P P+E P R$ BLEND}

Materials used for carrying out experiment is $\mathrm{PP}+\mathrm{EPR}$ that is polypropylene+ethylene propylene. EPR is a type of elastomer which is cured with sulphur. The inclusion of elastomer helps in rise of toughness however it leads to reduction of the stiffness. EPR additives help to lower crack propagation rate. The addition of supple material acts as collision modifier, contributing improvement in the impact behavior. Addition of EPR in PP find areas of application in packaging, automotive bumpers, fender lines, interior, instrumental panels and industrial application.

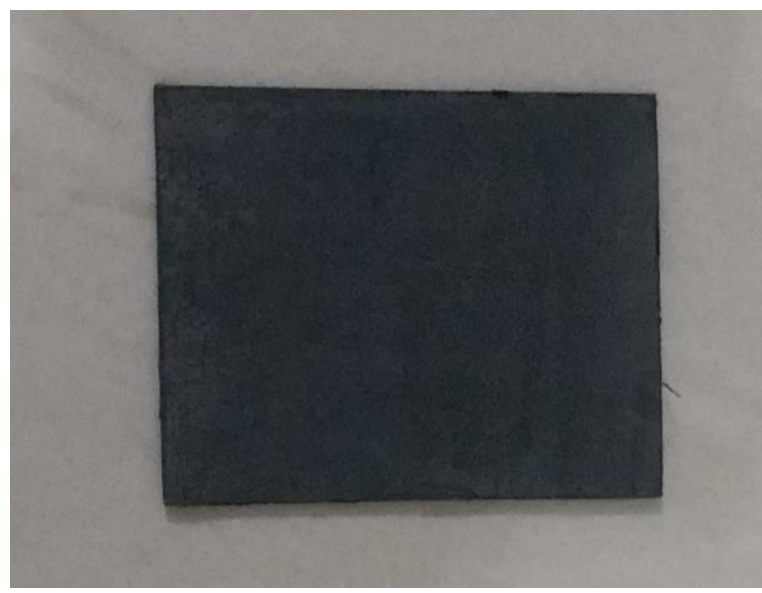

Fig 2:- PP+EPR Material
The material sheet used was aged plastic to check out the reparability of plastic after a deformity stages. The blends of PP+EPR in weight proportion are about $72 \% \mathrm{PP}$ and $22 \%$ EPR. Cristallinity of the material is about $48 \%$, density of the material is $0.90 \mathrm{~g} / \mathrm{cm}^{3}$.

\section{EXPERIMENTAL WORK}

In the experimental work the main focus is on evaluation of hot gas welding technique by considering critical parameters which directly affects the strength of weld created on the specimens. The material used for carrying the experimental investigation is $\mathrm{PP}+\mathrm{EPR}$ blend plastic which is widely use for manufacturing of technical parts and mechanical structures etc Proposed methodology for experimental work is shown in fig. no 3 , it consist of exact flow of the work.

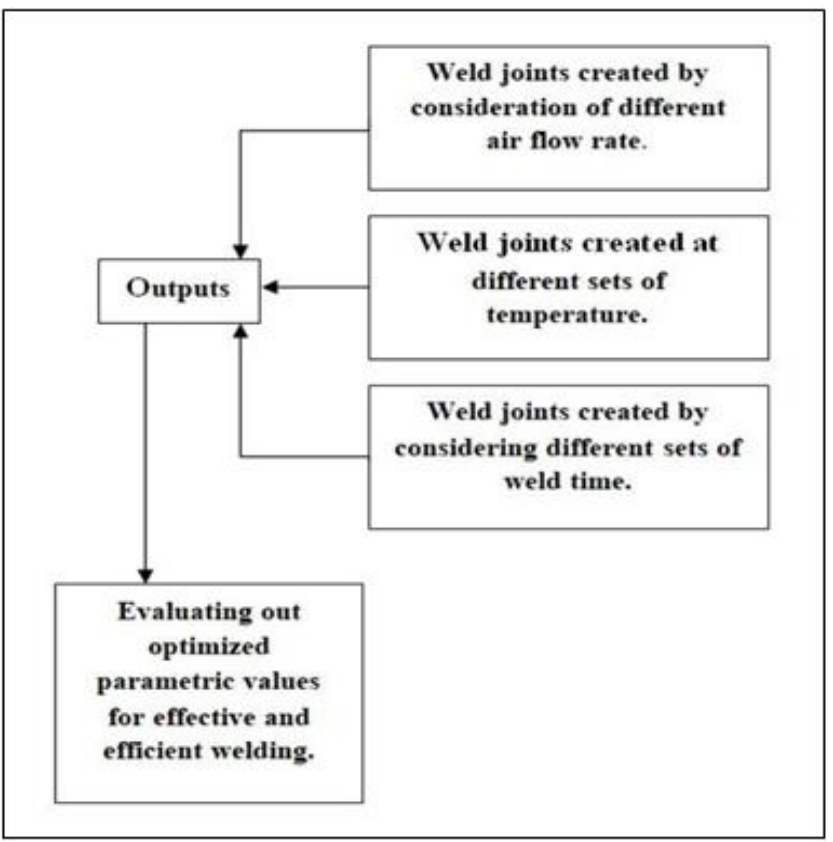

Fig 3:- Experimental methodology.

All the work is divided into three cases A, B, C by consideration of critical parameters as mentioned in table no 1. In case A, the work was determined for the best outcome in terms of air flow rate. In case B, evaluation of values was done at different sets of temperature at two different air flow rate for exact outcome in combination of airflow rate and temperature. In case $\mathrm{C}$, the experimental outcomes from cases $A \& B$ were used with combination of different weld time for best outcome by analysis of all three cases.

\begin{tabular}{|c|c|c|}
\hline Sr no. & \multicolumn{2}{|c|}{ Considered critical parameters. } \\
\hline 1. & $\begin{array}{c}\text { Air flow rate } \\
\text { (AFR) }\end{array}$ & $\begin{array}{c}2401 \mathrm{pm} \\
4501 \mathrm{pm}\end{array}$ \\
\hline 2. & Temperature & $280^{\circ} \mathrm{C}, 320^{\circ} \mathrm{C}$, \\
& & $360^{\circ} \mathrm{C}, 400^{\circ} \mathrm{C}$. \\
\hline 3. & Weld time & $60 \mathrm{~s}, 65 \mathrm{~s}, 70 \mathrm{~s}$, \\
& (seconds) & $75 \mathrm{~s}, 80 \mathrm{~s}, 85 \mathrm{~s}$, \\
& & $90 \mathrm{~s}$. \\
\hline
\end{tabular}

Table 1:- Parameters for experimental work. 
ISSN No:-2456-2165

The hot air gun used for creating weld was DEWALT(D26414) having power input of 2000watts, voltage of 220-240 volts. It consists of LCD control display for determining the output controls. It has temperature range from $50^{\circ} \mathrm{C}$ to $600^{\circ} \mathrm{C}$, which is enough to carry out polymer welding. Temperature range can be changed by using control buttons near control display.

For welding the specimens angle between the gas nozzle and weldment was $45^{\circ}$ with the gap distance of $10 \mathrm{~mm}$ which was constant for each cases throughout the experimental work. For performing the experiment the specimens used are of dog bone type, the specimens were created by considering the standards for carrying out tensile testing, which is performed on microtech tensometer.

\section{RESULTS AND OBSERVATIONS}

\section{A. Case A}

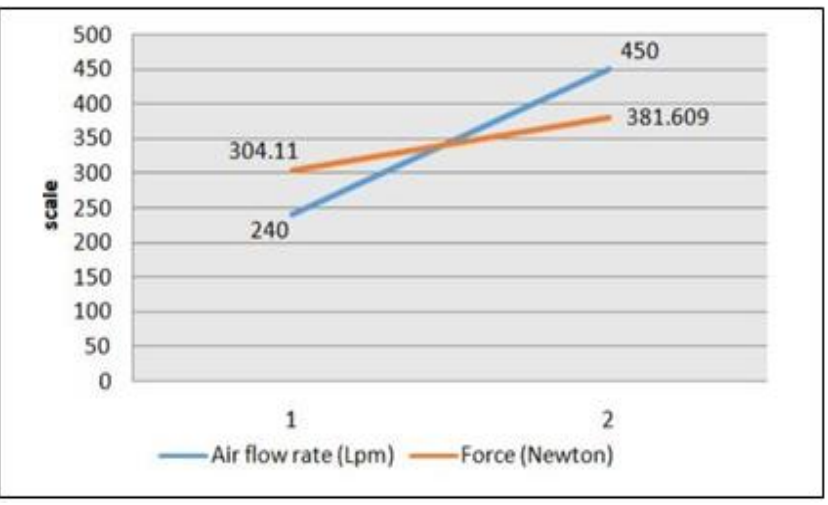

Fig 4:- Force Sustained at Different Air Flow Rate.

In case (A) main focus was to get the air flow rate which is most appropriate for welding. It was done by considering airflow rate of 2401pm and 4501pm. For further proceeding of the experimental investigation as there were no specified values for temperature and time it was taken randomly $300^{\circ} \mathrm{C}$ and $70 \mathrm{sec}$. At AFR of 2401pm the load sustained was $304.11 \mathrm{~N}$ and at $4501 \mathrm{pm}$ it was $381.609 \mathrm{~N}$ as shown in fig no 4.

\section{B. Case B}

\begin{tabular}{|c|c|c|c|}
\hline Sr & Temperature $\left({ }^{\mathbf{0}} \mathbf{C}\right)$ & \multicolumn{2}{|c|}{ Force (Newton) } \\
\cline { 3 - 4 } no. & & $240 l p m$ & $450 l p m$ \\
\hline 1. & 280 & 258.03 & 333.54 \\
\hline 2. & 320 & 291.35 & 316.86 \\
\hline 3. & 360 & 363.9 & 264.87 \\
\hline 4. & 400 & 353.16 & 235.44 \\
\hline
\end{tabular}

Table 2:- Force at Different Temperature And Air Flow Rate.

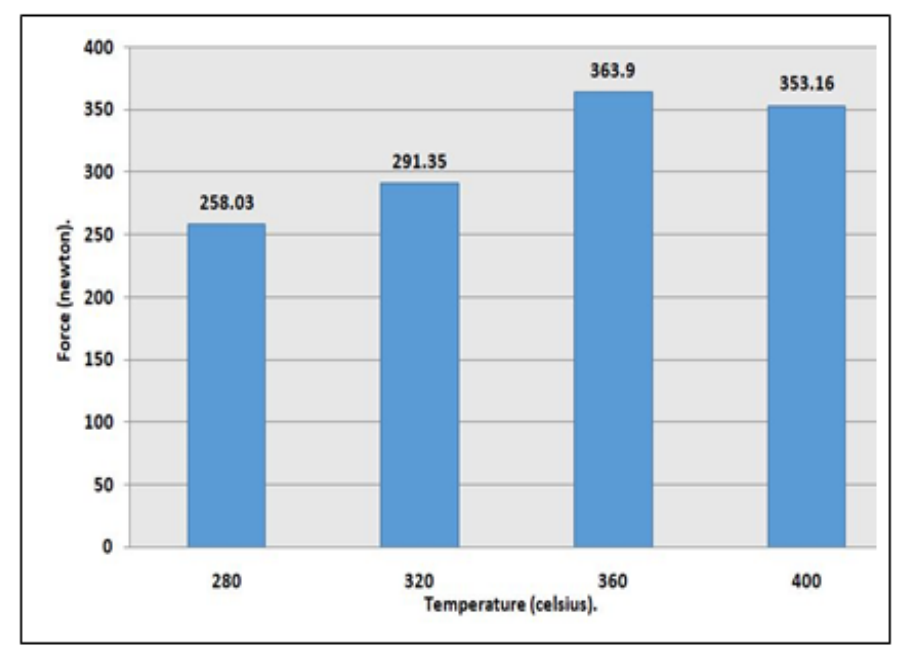

Fig 5:- $(240 \mathrm{lpm})$ Force Sustained at Different Temperature.

In case $\mathrm{B}$, the experimental work is done to get best combination of AFR and temperature for welding. It was carried out in consideration of two parts one at AFR 240lpm for different temperature as shown in fig no 4 and in other part at AFR of 4501pm as shown in fig no 5 .

While keeping AFR of 2401pm constant for all the temperature it has seen that at $280^{\circ} \mathrm{C}$ load sustained was $258.03 \mathrm{~N}$ with the increase in temperature load sustainability also increased. At $360^{\circ} \mathrm{C}$ maximum load attended is $363.9 \mathrm{~N}$ after that $400^{\circ} \mathrm{C}$ the load sustained get reduced to $353.16 \mathrm{~N}$. It has also seen that in fig no 5 at AFR of $4501 \mathrm{pm}$ at low temperature of $280^{\circ} \mathrm{C}$ the load sustained is $333.54 \mathrm{~N}$ but it starts gradually reducing with increase in temperature, it is due to excess air flow at surface with increase in temperature causing oxidation and reduction of strength in material. As temperature increased to $400^{\circ} \mathrm{C}$ at $4501 \mathrm{pm}$ the weld occur was inacceptable due bad surface.

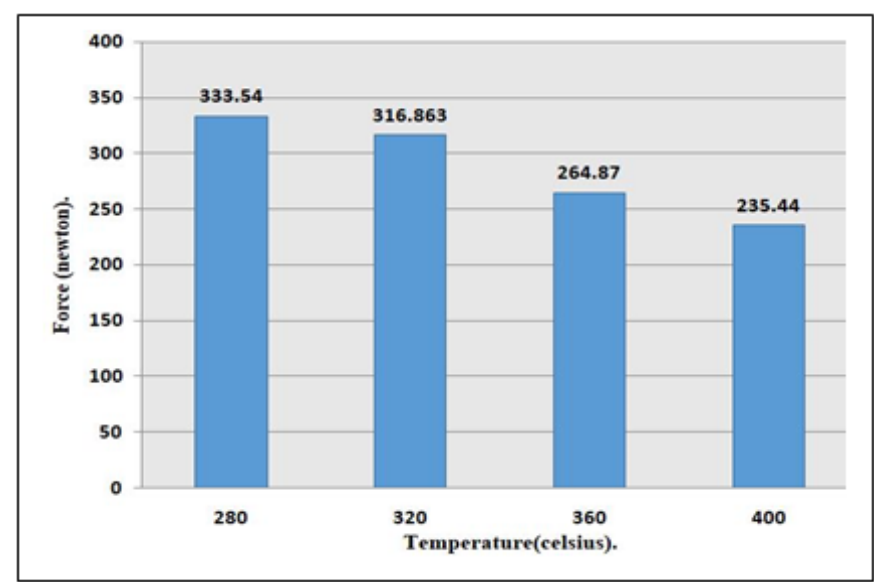

Fig 6:- (450 lpm) Force Sustained at Different Temperature. 


\section{Case C}

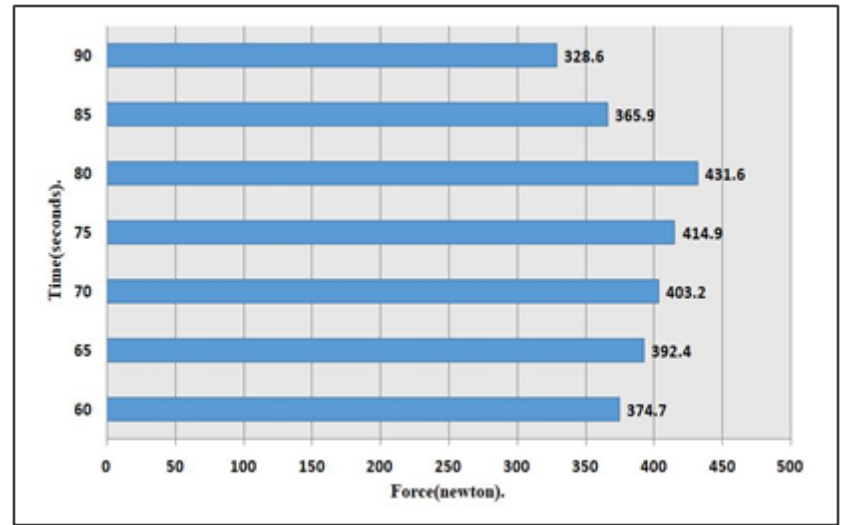

Fig 7:- Force Sustained at Different Weld Time.

In case $\mathrm{C}$, values are taken from previous experimentation cases $\mathrm{A} \& \mathrm{~B}$. The main approach of case $\mathrm{C}$ is to get exact time span for carrying out welding. At different time each specimen was welded and testing is been carried out. Minimum 60sec was required to carry out weld before that material softening was not enough for welding. As the time was increasing load taken by specimen was also increasing till $85 \mathrm{sec}$ after that force sustained was depreciating. Force sustained at $90 \mathrm{sec}$ was reduce due to excessive heat accommodation at one place causing shape deformation. At $80 \mathrm{sec}$ maximum force was sustained about $431.6 \mathrm{~N}$ as shown in fig no 7 .

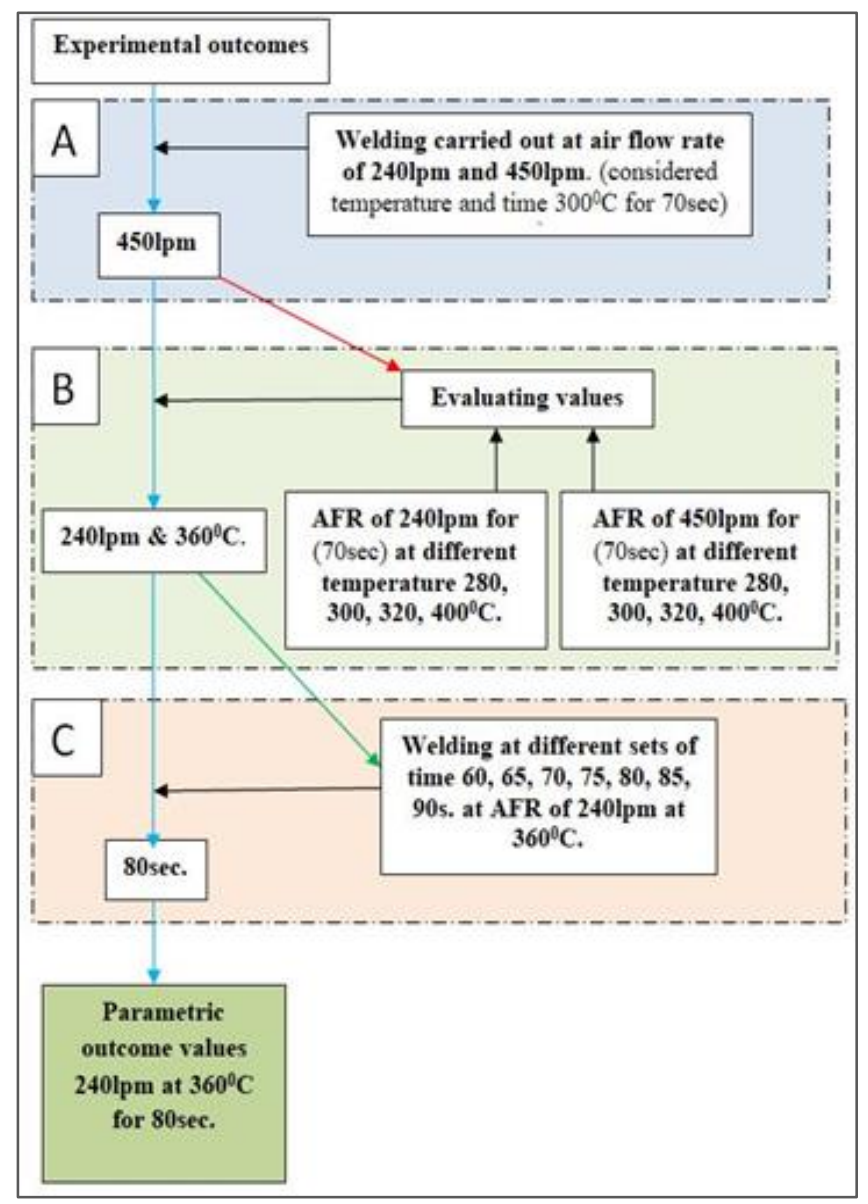

Fig 8:- Experimental Outcomes.

\section{CONCLUSIONS}

While performing hot gas welding process some amount of heat energy get lost in atmosphere due to convection which cause to work at higher temperature rate to overcome the loss.

$>$ Air flow rate of 2401pm is more suitable as compared to $4501 \mathrm{pm}$. As weld joint with 2401pm can sustain more load at different temperature. Joints with $4501 \mathrm{pm}$ proven to be more hard and brittle, having greater heat affected zone.

$>$ At $360^{\circ} \mathrm{C}$ most effective weld joints can form capable of sustaining force of $363.9 \mathrm{~N}$. Whereas at $280{ }^{\circ} \mathrm{C}$ the temperature at the surface was not enough to create complete welds, while at $400^{\circ} \mathrm{C}$ surface was deforming at greater extend.

$>$ For perfect welds, time of 80 seconds should be considered. If it exceeds more than 90 seconds geometrical distortion can be seen over the specimens.

$>$ Parametric values extracted by experimentations for creating weld joints of $\mathrm{PP}+\mathrm{EPR}$ blend material is at air flow rate of $2401 \mathrm{pm}$ at $360^{\circ} \mathrm{C}$ for a time period of $80 \mathrm{sec}$.

\section{REFERENCES}

[1]. Onur Balkan, Halil Demirer, Ayhan Ezde, Huseyin Yildırım, "Effects of Welding Procedures on Mechanical and Morphological Properties of Hot Gas Butt Welded PE, PP, and PVC Sheets", Wiley Polymer Engineering and Science DOI10.1002/pen.21014, Turkey (2008).

[2]. Kamran Ali, Shara Khursheed, "Analysis Of Heat Affected Zone (Haz) Of Hot Air Welded PVC (Polyvinyl Chloride) At Different Combination Of Input Parameters", International Research Journal Of Engineering and Technology, e-ISSN: 2395-0056, Vol.5, India (2018).

[3]. Hoomam Ahamad, Anees Siddiqui, Shyam Narayan Pandey, Amir Javed, Shagufta Naz, " Effect Of Temperature On Mechanical Behavior Of Hot Air Welded PMMA", International Journal of Technical Research and Applications e-ISSN:2320-8163,Vol.4, (2016).

[4]. A.S.Khedvan and Dr. K.P. Kolhe, “ Development Of Hot Air Plastic Welding Machine For Welding Of Polypropylene Material". Journal Of Emerging Technologies And Innovative Research, ISSN-23495162 Vol.3 Pune, India, (2016).

[5]. Mahmood Alam, Dr. M. I. Khan, "State Of The Art In Rigid PVC Plastic Welding By Hot Air Techinique", IJTRA, PP. 215-219, Vol.1,(2013).

[6]. Hoomam Ahamad, Md Shakibul Haque, Mahmood alam, Shyam narayan Pandey, Mohd. Amanuddin, "Welding Of Plastics Through Hot Gas Techinique: A Review", Global research and development journal for engineering, e-ISSN:2455-5703, Vol.1, (2016).

[7]. Senem Kursun Bahadir, Fatma Kalaoglu, Simona Jevsnik, "The Use Of Hot Air Welding Technologies For Manufacturing E-Textile Transmission Lines", Fibers And Polymers, ISSN :1229-9197, Vol.16, (2015). 
[8]. O. Balkan, H. Demirer, H. Yildirim, "Morphological And Mechanical Properties Of Hot Gas Welded PE, PP And PVC Sheets", Journal Of Achievements In Materials And Manufacturing Engineering, Vol.31, (2008).

[9]. Fawad Tariq, Nausheen Naz, Muhammad Amir Khan, Rasheed Ahmed Baloch, "Faliure Analysis Of High Density Polyethylene Butt Weld Joint", ASM International Spinger, (2011).

[10]. D. Grewell, A. Benatar, "Welding Of Plastics: Fundamentals And New Developments", Polymer Processing XXII, Iowa State University, USA, (2007).

[11]. L. Zhang and P. Michaleris, "Evaluation of applied plastic strain methods for welding distortion prediction", Journal Of Manufacturing Science And Engineer ASME, Vol.129, (2007).

[12]. B. Marczis, T. Czigany, "Interrelationship Between Welding Parameters Of Hot Gas Welded Polypropylene", Polymer Engineering And Science, Wiley intrscience, (2006).

[13]. Dr. Haider Hadi Jasim, "Evaluation the Effect of Residual Stress on Fracture of Polyethylene Pipe under Pressure Loading", Basrah Journal for Engineering Sciences, vol. 16, no. 2, (2016).

[14]. J.Sims P.A Ellwood, "Pollutants From Laser Cutting And Hot Gas Welding Of Plastics", British occupational health society, oxford journal, Pennsylvania, (2016).

[15]. Patricia M. Frotini, Laur A. Fasce, "Failure Analysis Of Polypropylene Block Copolymer Welded Joints.", Institute of polymer and materials, Argentina. 